\title{
Experiences and attitudes of residents regarding a community-based genome cohort study in Japan: a population-based, cross-sectional study
}

\author{
Keiko Miyamoto ${ }^{1 *}$, Miho Iwakuma ${ }^{1}$ and Takeo Nakayama²
}

\begin{abstract}
Background: Because of the rapid development in genomics, more research findings have emerged. However, the association between society and research results remains controversial. This article examines the experiences and attitudes of residents regarding a community-based genomic cohort study.

Methods: This study was conducted as a part of the health survey of the City Health Promotion section. At the conclusion of the first stage of the project, a self-administered questionnaire was mailed to a random sample of 2,500 residents in 2012.

Results: The response rate was $59 \%(n=1477 / 2500)$. The findings show that $70 \%$ of males and $50 \%$ of females knew nothing about the project. Females and elderly people were more likely to have knowledge of the study, indicating that self-rated understanding of the terminology is statistically associated with the level of awareness regarding the project. In addition, those who were aware of the project were also aware of the benefits of research utilizing genetic information, whereas unaware respondents, particularly males, believed that unexpected negative effects may occur. Those with higher self-rated understanding of the terminology and higher awareness of benefit of the research utilizing genetic information had more positive attitudes toward undergoing drug susceptibility genetic testing, indicating that the awareness of project in females and concerns toward genetic research are not statistically associated with the willingness to undergo.

Conclusions: This study suggests that a community-based genome cohort project helps raise awareness of benefit of genetic research and that knowledge, however, does not directly affect the willingness to participate in related activities, such as drug susceptibility genetic testing. Therefore, additional research that focuses on the circular relationship between risk and action must be conducted in the future.
\end{abstract}

Keywords: Public attitude, Genome study, Drug susceptibility, Familiarity, Japan

\section{Background}

Since the human genome was sequenced in 2003, the field of genome epidemiology has produced numerous studies on the complex relationships between phenotypes and genotypes [1]. The focus has shifted away from medical institutions to communities, which has created a greater need for members of the general public

\footnotetext{
* Correspondence: miyamoto.keiko.87w@st.kyoto-u.ac.jp

${ }^{1}$ Department of Medical Communication, Kyoto University School of Public

Health, Yoshidakonoe-cho, Sakyo-ku, Kyoto \#6068501, Japan

Full list of author information is available at the end of the article
}

to provide sensitive information regarding their genetics, lifestyle habits, and medical histories depending on trust $[2,3]$. Therefore, public attitudes toward genome research can significantly affect willingness to support such studies.

The increase in genomic studies has also shown the difficulty of applying study outcomes to clinical practice [4-6]. Direct-to-consumer genetic testing that bypasses medical settings $[7,8]$ has also become controversial. In addition, because of accumulating evidence that drug susceptibility can differ depending on genotypes, there 
are persistent expectancies for personalized medicine based on pharmacogenomics [9-11]. Better understanding of public attitudes and awareness toward genome studies could thus lead to improved integration of genome research into medical plans and procedures $[12,13]$.

In 2005, the Kyoto University Graduate School of Medicine and the city of Nagahama initiated the Nagahama Study for Comprehensive Human Bioscience (hereafter referred as the Nagahama study) to promote the health of Nagahama citizens, develop community-based genomicepidemiologic studies, and create a biobank. In particular, the Nagahama study examined the effects of the complex gene-environment interaction on diseases by storing biological samples of Nagahama residents (aged 30-74 years) and following their conditions for 10 years. The main study began in November 2008. From November 2006 to November 2010, the Kyoto University researchers held 13 public forums on contemporary medical issues, such as the genome, lifestyle-related diseases, sleep disorders, information disclosure, and hospital evaluations for residents or high school students. These meetings included six symposia and five "science café" talks; these events are ongoing. For recruitment, the Nagahama City Health Promotion section provided leaflets through resident associations and placed announcements in Nagahama-area media regarding the study program. In addition, residents aged 30-39 were contacted by mail, while those aged 40-74 were asked to serve as an alternative of the national health check-up program in Japan. Ultimately, 10,084 citizens ( $14 \%$ of the eligible people) participated in the Nagahama study program. According to the findings of a 2009 midterm study on citizens' awareness of and attitudes toward the program, the most commonly cited positive aspect of the Nagahama study was the "free and extensive health check-up program." Half of those who had participated in Nagahama study knew the Nagahama study was a genome study [14].

There are several quantitative studies regarding public attitudes toward genome studies [15-19]. They suggest that the majority of lay people have positive attitudes toward genome studies. In some studies, positive attitudes toward genome studies were associated with genome literacy $[16,17]$. However, because the respondents' attitudes were changeable depending on the contexts, the authors concluded that negative attitudes do not simply reflect a lack of understanding $[15,20,21]$. Sturgis \& Allum [22] suggested that the knowledge of science engenders positive attitudes toward science. However, it may be useful to integrate knowledge and context to understand the public attitudes toward science because science is not isolated in society.

Another background characteristic associated with positive attitudes toward genome study is familiarity or the experience of genetic study and awareness of terminology $[15,17]$. The Dutch study by Henneman et al. [16] clarified that respondents who have heard of genetic testing anticipated greater importance of the genetic aspects of diseases. They suggested that those who were familiar with a genetic disease were more likely to support the use of genetic tests and that the respondents' attitudes were not always associated with the level of genetic knowledge.

Some studies have focused on the association between familiarity and public attitudes toward nanotechnology [23-25], while toward genetic testing are limited. Henneman et al. [26] conducted a survey in 2010 (in addition to 2002) about public attitudes toward genome studies and investigated the change in attitudes over the preceding 8 years. Their results revealed that people were more interested in their own genetic makeup, but experience in genetic testing had not changed. In Nagahama, Miyamoto et al. [14] clarified that the Nagahama study was accepted by the general public, who were somewhat disconnected from the world of science. Therefore, by focusing on their experiences, this study examines how a community-based genomic-epidemiologic study affected the residents' attitudes toward genome studies. In addition, the association between residents' experiences and willingness to participate in drug susceptibility genetic testing was explored.

\section{Method}

\section{Participants and setting}

This study was conducted as a part of the health and lifestyle survey of the Nagahama City Health Promotion section to examine the health consciousness of the residents of Nagahama. Data were collected using an anonymous self-administered postal questionnaire in March and April 2012. The return of the questionnaire was viewed as implied consent. In compliance with local regulations, a random sample of 2,500 subjects (aged 30-69 years) was selected from the Basic Resident Register. The study protocol was approved by the Kyoto University Graduate School and Faculty of Medicine Ethics Committee.

\section{Measures}

The questionnaire was developed on the basis of preliminary surveys conducted during earlier phases of the Nagahama study $[14,27]$ and the nationwide survey on public attitudes toward genetic studies in Japan [17]. Revisions were made according to advice from public health researchers and staff members of the Nagahama City Health Promotion section. The survey items are listed below.

\section{Attitudes toward the use of genetic information for medical purposes}

The three "awareness of benefit" items were "helpful for disease diagnosis," "helpful for disease treatment," and 
"helpful for disease prevention." The five "concern" items were "studies require financial infusion," "privacy concerns are raised," "discrimination in employment and when purchasing insurance is generated," "cloned human beings come into existence," and "unexpected negative effects may be raised" and one "belief" item was "companies or government bodies use genome information." The answers were scored on a five-point Likert scale ranging from 1 (completely disagree) to 5 (completely agree).

\section{Willingness to participate in drug susceptibility genetic testing}

On the basis of a hypothetical scenario, the following was included in the survey: "Hypothetically speaking, there is a drug that has a good effect on some, whereas it has an adverse effect on others. When you undergo drug susceptibility genetic testing, you are informed of the drug's effectiveness or adverse effects. Would you still donate your DNA for the test?" The answer was scored on a five-point Likert scale ranging from 1 (never) to 5 (definitely yes).

\section{Individual factors}

In addition to the survey items, each participant was asked to provide socio-demographic characteristics (age, sex, employment status, and formal education duration). The latter question's responses were dichotomized to less than 12 years (high school graduate and lower) or more than 13 years (college and higher). Participants were also surveyed as to the level of awareness regarding the three aspects of the Nagahama study (the extensive health check-up program, follow-up study, and genome studies). The awareness of the Nagahama study was dichotomized between "High awareness of the Nagahama study (those who knew more than one content)" and "Low awareness of the Nagahama study (those who knew nothing about the study's content). Furthermore, the participants were surveyed on the self-rated understanding of the terms "genome" and "gene." Answers to the questions consisted of the following: "I understand it," "I have heard of it," and "I have never known about it." Then, the respondents were divided into three groups: "High" knowledge level was defined as understanding both terms or understanding "gene" and having heard of "genome;" "middle" knowledge was defined as having heard of both of terms or understanding "gene" and having never known about "genome;" and "low" knowledge was defined as having heard of "gene" and not "genome" or having never known about both the terms.

\section{Analyses}

All data analyses were performed using SPSS version 22.0 J for Microsoft Windows. Chi-square tests were used to examine associations between the items. The difference was considered significant at $p<0.05$ (two-sided test). Logistic regression analyses were employed to identify factors associated with the awareness of benefits of genome study and the willingness to undergo the drug susceptibility genetic testing as dependent variables, respectively. Both dependent variables were dichotomized between those who agreed with the questions versus neutral/disagree.

\section{Results \\ Respondents' characteristics}

Out of the 2,500 questionnaires distributed, 1,477 were returned (59.1\% response rate). Two blanks and two of unknown sex were excluded for a total of 1,473. Demographic and individual factors including awareness of the research contents of the Nagahama study and self-rated understanding of the terminology are presented in Table 1. Overall, males (47.8 \%) in their 30s (18.5\%) and 40s (21.5\%) and those having completed less than 12 years of formal education (57.6\%) were underrepresented.

As for the awareness of project's contents, respondents were asked whether they knew about the three aspects of the Nagahama study. According to the results, $9.8 \%$ of the males and $14.5 \%$ of the females knew about all three items; $20.5 \%$ of the males and $35.8 \%$ of the females knew about one or two items; and $69.7 \%$ of the males and $49.7 \%$ of the females knew none of the three. With regard to self-rated understanding of the terms "genome" and "gene," "High" knowledge level as understanding both terms $(n=159)$ or understanding "gene" and having heard of "genome" $(n=277)$ was $30.2 \%$; the "middle" level as having heard of both of terms $(n=377)$ or understanding "gene" and having never known about "genome" ( $n=139)$ was $35.7 \%$; and "low" knowledge consisted of having heard of "gene" and not "genome" $(n=$ 472) or having never known about both terms $(n=20)$ was $34.1 \%$. Males were more prevalent in the high level than females $\left[\chi^{2}(2)=28.47, p<0.001\right]$.

Respondents who knew about all or some of the items ( $n=591)$ were $40.7 \%$ and those who knew nothing ( $n=859)$ were $59.3 \%$. Males and younger people were less aware of the Nagahama study [male, $\chi^{2}(1)=60.10$, $p<0.001$; younger, $\left.\chi^{2}(3)=19.90, p<0.001\right]$. There was no significant difference in educational status regarding awareness of the Nagahama study $\left[\chi^{2}(1)=2.26, p=0.133\right]$. Awareness of the Nagahama study predicted a significantly higher level of understanding of the terms "gene" and "genome" $\left[\chi^{2}(2)=20.77, p<0.001\right]$ (Table 2).

\section{Attitudes toward the use of genetic information for medical purposes}

More than $80 \%$ of respondents agreed that the use of genetic information for medical purposes is "helpful for 
Table 1 Demographic awareness of the Nagahama study, self-rate understanding of terminology, and willingness toward drug susceptibility genetic testing

\begin{tabular}{|c|c|c|c|c|}
\hline & \multicolumn{2}{|c|}{ Male $(n=704)$} & \multicolumn{2}{|c|}{ Female $(n=76$} \\
\hline & $\%$ & $n$ & $\%$ & $n$ \\
\hline \multicolumn{5}{|l|}{ Age group (years) } \\
\hline $30-39$ & 16.1 & 112 & 20.7 & 159 \\
\hline $40-49$ & 20.1 & 140 & 22.8 & 175 \\
\hline $50-59$ & 23.8 & 166 & 26.3 & 202 \\
\hline $60-69$ & 40.0 & 279 & 30.2 & 232 \\
\hline \multicolumn{5}{|l|}{ Formal educational period } \\
\hline High school graduate and lower & 59.1 & 392 & 56.3 & 414 \\
\hline College and higher & 40.9 & 271 & 43.8 & 322 \\
\hline \multicolumn{5}{|c|}{ Awareness of the Nagahama study contents } \\
\hline Know more than one content & 30.6 & 210 & 50.3 & 381 \\
\hline Know nothing & 69.7 & 483 & 49.7 & 376 \\
\hline \multicolumn{5}{|l|}{ Self-rated understanding of terminology } \\
\hline $\mathrm{High}^{\mathrm{a}}$ & 35.7 & 251 & 24.1 & 185 \\
\hline Medium ${ }^{b}$ & 35.1 & 247 & 35.0 & 269 \\
\hline Low $^{c}$ & 28.0 & 197 & 38.4 & 295 \\
\hline
\end{tabular}

Willingness toward drug susceptibility genetic testing (Would you like to donate your DNA for drug susceptibility genetic testing?)

\begin{tabular}{lllll} 
Yes & 49.3 & 339 & 47.9 & 360 \\
Neutral & 27.2 & 187 & 32.0 & 240 \\
No & 23.4 & 161 & 20.1 & 151 \\
\hline
\end{tabular}

"Understanding "gene" and "genome" and understanding "gene" and having heard of "genome"

"Having heard of "gene" and "genome" or understanding "gene" and having never known about "genome"

"Having of "gene" and not "genome" or having never known about "gene" nor "genome"

disease diagnosis," "helpful for disease treatment," and "helpful for disease prevention." All three "awareness of benefit" items exhibited high mutual correlations (Cronbach's alpha $=0.917)$. Less than half of the respondents agreed that "companies or government bodies use genome information," "discrimination in employment and when purchasing insurance is generated," "cloned human beings come into existence," and "unexpected negative effects may be raised." All five "concern" items also exhibited high mutual correlations (Cronbach's alpha $=0.794)$ (Fig. 1). Those who were aware of the Nagahama study showed significantly higher awareness of the benefit of genomic studies than those who were unaware [diagnosis, $\chi^{2}(1)=$ $36.93 p<0.001$; treatment, $\chi^{2}(1)=39.80, p<0.001$; prevention, $\left.\chi^{2}(1)=39.23, p<0.001\right]$. On the other hand, males who knew nothing showed significantly higher concerns that "unexpected negative effects may be raised" [ $\left.\chi^{2}(1)=4.50, p=0.034\right]$. However, other significant differences were not found between those who were aware of the Nagahama study and those who knew nothing about the study.

The effects of awareness of the Nagahama study, concerns, the belief that companies or government bodies might use genome information, and the self-rated understanding of the terminology were also examined in relation to the "awareness of benefits." According to the result, both males and females who were aware of the project's contents, perceived high and middle level of understanding of the terminology and the concern item of "studies require financial infusion" significantly agreed with the three awareness of benefit items of "helpful for disease diagnosis," "helpful for disease treatment," and "helpful for disease prevention." Particularly, in females, "cloned human beings come into existence" was positively and "unexpected negative effects may be raised" was negatively associated with the awareness of the benefit items (Table 3).

\section{Willingness to participate in drug susceptibility genetic testing}

When asked whether they would be willing to undergo drug susceptibility genetic testing, $48.5 \%$ of the respondents revealed positive attitudes, $29.7 \%$ could not decide, and $21.7 \%$ revealed negative attitudes (Table 1 ). Moreover, $55 \%$ of those who agreed that the use of genetic information for medical purposes is "helpful for disease treatment" were willing to undergo drug susceptibility genetic testing. There was no significant difference between males and females.

Logistic regression analyses were performed to examine the association of the willingness to participate in drug susceptibility genetic testing to be informed of the drug's effectiveness or adverse effects and attitudes toward genetic testing. According to the results presented in Table 4, males who were aware of the project's contents, had a high level of self-rated understanding of the terminology, and had high awareness of benefit of genetic testing for disease treatment were more willing to donate their DNA for drug susceptibility genetic testing compared with the reference group of males who were unaware of the Nagahama study, perceived their understanding of terminology middle and low, and had a low awareness of the benefit of genetic testing for disease treatment. Females who had high and middle levels of self-rated understanding of the terminology and had high awareness of benefit of genetic testing for disease treatment were more willing to undergo drug susceptibility genetic testing than the reference group of females who perceived their understanding of terminology low and had a low awareness of the benefit of genetic testing. There was no association with positive attitude toward such testing and awareness of the project's contents in females. Significant differences were not observed between 
Table 2 Differences in individual factors between those who were aware of the Nagahama study and those who knew nothing about the Nagahama study from Qui-square test

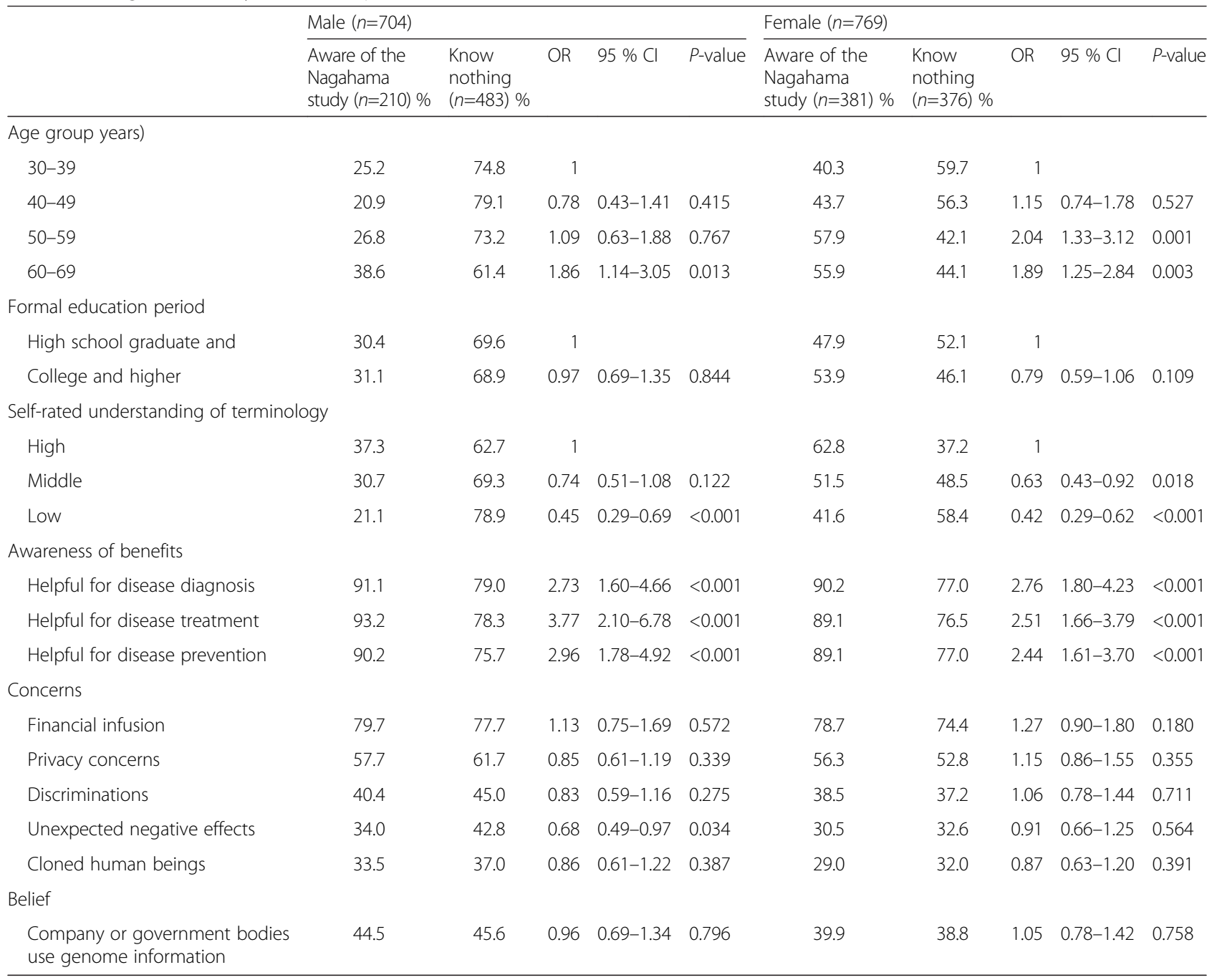

the willingness to participate in drug susceptibility genetic testing and either concerns about genome studies or the belief of usage of genome information in companies or government bodies in both sexes.

\section{Discussion}

This article examined the effects of a community-based genomic-epidemiologic study on residents of Nagahama, Japan regarding their attitudes toward the project and genetic testing.

Respondents who were aware of the contents of the study perceived their understanding of terminology to be high. This was contrary to our expectation that the awareness of the study contents did not correlate with their self-rated understanding terminology as Nagahama City and Kyoto University try hard to keep every citizen informed about the Nagahama study by providing leaflets several times to all houses [14]. One reason might be that participants in the Nagahama study could enhance their understanding of terminology through the study's briefing paper, and another reason might be that those who were interested in genome studies could also attend symposia or science cafés because science communication activities are mainly accepted by those who are already interested in science and have positive attitudes toward science, as Gottweis [28] suggested.

Previous studies have shown that the public generally has positive attitudes toward genetic studies [15-19]. Similarly, the present study found that more than $80 \%$ of the respondents were aware of the benefits of genetic studies. Those who were aware of the project's contents and perceived their comprehension of the terminology well were more aware of the benefits than those who had lower awareness. This result supports the idea that 
Helpful for disease diagnosis

Helpful for disease treatment

Helpful for disease prevention

Studies require financial infusion

Privacy concerns are raised

Company or goverment bodies use genome information

Discriminations in employment and when purchasing insurance is generated

Unexpected negative effects may be raised

Cloned human beings come into existence

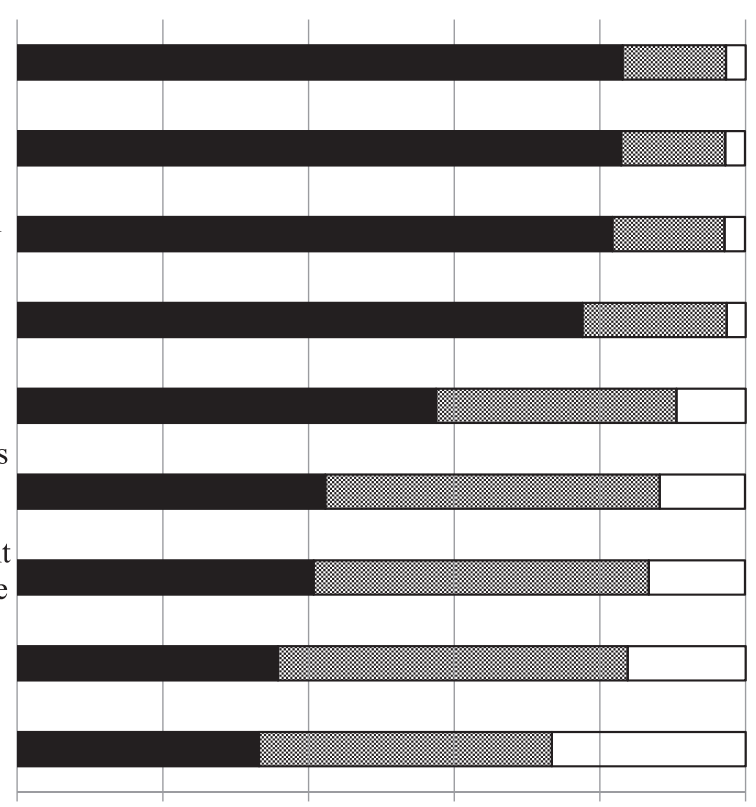

$0.0 \%$

$20.0 \%$

$40.0 \%$

$60.0 \%$

$80.0 \% \quad 100.0 \%$

agree $\quad$ a can not decide $\quad$ adisagree

Fig 1 Attitudes toward the use of genetic information for medical purposes

Table 3 Relationship between awareness of the benefit of genome study and awareness of the Nagahama study, self-rated understanding of terminology, concern, and belief of usage of genetic information in companies or government bodies from Logistic Regression Analysis

\begin{tabular}{|c|c|c|c|c|c|c|c|c|c|c|}
\hline & \multirow{2}{*}{\multicolumn{2}{|c|}{$\begin{array}{l}\text { Male ( } n=704) \\
\text { The use of genetic } \\
\text { information is helpful } \\
\text { for disease treatment }\end{array}$}} & & & & \multirow{2}{*}{\multicolumn{2}{|c|}{$\begin{array}{l}\text { Female }(n=769) \\
\text { The use of genetic } \\
\text { information is helpful } \\
\text { for disease treatment }\end{array}$}} & \multirow{4}{*}{$\overline{O R^{a}}$} & \multirow{4}{*}{$95 \% \mathrm{Cl}$} & \multirow{4}{*}{$P$-value } \\
\hline & & & & & & & & & & \\
\hline & \multirow{2}{*}{$\begin{array}{l}\text { Agree } \\
(n=554) \\
\mathrm{n}(\%)\end{array}$} & \multirow{2}{*}{$\begin{array}{l}\text { Neutral or } \\
\text { Disagree } \\
\mathrm{n}(\%)\end{array}$} & \multirow[t]{2}{*}{$\overline{\mathrm{OR}^{\mathrm{a}}}$} & \multirow[t]{2}{*}{$95 \% \mathrm{Cl}$} & \multirow[t]{2}{*}{$P$-value } & \multirow{2}{*}{$\begin{array}{l}\text { Agree } \\
(n=591) \\
\mathrm{n}(\%)\end{array}$} & \multirow{2}{*}{$\begin{array}{l}\text { Neutral or } \\
\text { Disagree } \\
\text { n (\%) }\end{array}$} & & & \\
\hline & & & & & & & & & & \\
\hline High awareness of the Nagahama study & $191(34.8)$ & $14(12.4)$ & 3.82 & $1.93-7.57$ & & $326(55.6)$ & $40(33.3)$ & 2.63 & $1.63-4.24$ & $<0.001$ \\
\hline \multicolumn{11}{|l|}{ Self-rated understanding of terminology } \\
\hline High & $231(41.8)$ & $19(16.5)$ & 1 & & & $168(28.8)$ & $15(12.6)$ & 1 & & \\
\hline Middle & $206(37.3)$ & $30(26.1)$ & 0.66 & $0.34-1.29$ & 0.223 & $224(38.4)$ & $37(31.1)$ & 0.72 & $0.36-1.42$ & 0.342 \\
\hline Low & $116(21.0)$ & $66(57.4)$ & 0.24 & $0.12-0.46$ & $<0.001$ & $192(32.9)$ & $67(56.3)$ & 0.49 & $0.27-0.98$ & 0.045 \\
\hline \multicolumn{11}{|l|}{ Concerns } \\
\hline Financial infusion & $456(84.0)$ & $60(52.2)$ & 4.37 & $2.49-7.69$ & $<0.001$ & $473(81.4)$ & $65(53.7)$ & 2.98 & $1.79-4.97$ & $<0.001$ \\
\hline Privacy concerns & $343(62.5)$ & $56(49.6)$ & 0.72 & $0.39-1.32$ & 0.284 & $335(56.9)$ & $53(43.8)$ & 1.00 & $0.57-1.74$ & 0.993 \\
\hline Discriminations & $250(45.3)$ & $39(34.2)$ & 1.38 & $0.74-2.58$ & 0.315 & $234(39.9)$ & $38(31.4)$ & 0.77 & $0.43-1.38$ & 0.386 \\
\hline Unexpected negative effects & $228(41.4)$ & $38(33.0)$ & 1.02 & $0.54-1.93$ & 0.963 & $192(32.6)$ & $33(27.5)$ & 0.49 & $0.26-0.90$ & 0.022 \\
\hline Cloned human beings & $203(37.0)$ & $35(30.4)$ & 0.87 & $0.46-1.66$ & 0.682 & $191(32.5)$ & $24(20.2)$ & 2.27 & $1.16-4.46$ & 0.017 \\
\hline \multicolumn{11}{|l|}{ Belief } \\
\hline $\begin{array}{l}\text { Company or government } \\
\text { bodies use genome information }\end{array}$ & $267(48.8)$ & $33(29.7)$ & 1.35 & $0.77-2.36$ & 0.299 & $251(42.7)$ & $30(25.0)$ & 1.71 & $0.98-3.00$ & 0.060 \\
\hline
\end{tabular}

${ }^{a}$ Adjusted according to age and formal education duration 
Table 4 Relationship between the willingness toward drug susceptibility genetic studies and the attitudes toward genome studies from Logistic Regression Analysis

\begin{tabular}{|c|c|c|c|c|c|c|c|c|c|c|}
\hline & \multicolumn{2}{|c|}{$\begin{array}{l}\text { Male }(n=704) \\
\text { Willingness toward } \\
\text { drug susceptibility } \\
\text { genetic studies }\end{array}$} & \multirow{3}{*}{$O R^{a}$} & \multirow{3}{*}{$95 \% \mathrm{Cl}$} & \multirow{3}{*}{$P$-value } & \multicolumn{2}{|c|}{$\begin{array}{l}\text { Female }(n=769) \\
\text { Willingness toward } \\
\text { drug susceptibility } \\
\text { genetic studies }\end{array}$} & \multirow{3}{*}{$O R^{a}$} & \multirow{3}{*}{$95 \% \mathrm{Cl}$} & \multirow{3}{*}{$P$-value } \\
\hline & Yes $(n=339)$ & $\begin{array}{l}\text { Neutral or } \\
\text { No }(n=348)\end{array}$ & & & & Yes $(n=360)$ & $\begin{array}{l}\text { Neutral or } \\
\text { No }(n=391)\end{array}$ & & & \\
\hline & n (\%) & n (\%) & & & & n (\%) & $\mathrm{n}(\%)$ & & & \\
\hline High awareness of the Nagahama study & $131(38.9)$ & $77(22.5)$ & 2.06 & $1.40-3.03$ & $<0.001$ & $200(56.0)$ & $178(46.4)$ & 1.28 & $0.92-1.79$ & 0.150 \\
\hline \multicolumn{11}{|l|}{ Self-rated understanding of terminology } \\
\hline High & $162(47.9)$ & $88(25.3)$ & 1 & & & $117(32.8)$ & $67(17.5)$ & 1 & & \\
\hline Middle & $120(35.5)$ & $124(35.6)$ & 0.58 & $0.39-0.87$ & 0.008 & $148(41.5)$ & $119(31.2)$ & 0.81 & $0.53-1.22$ & 0.307 \\
\hline Low & $56(16.6)$ & $136(39.1)$ & 0.33 & $0.20-0.54$ & $<0.001$ & $92(25.8)$ & $196(51.3)$ & 0.35 & $0.22-0.55$ & $<0.001$ \\
\hline $\begin{array}{l}\text { The use of genetic information } \\
\text { is helpful for disease treatment }\end{array}$ & $311(94.0)$ & $241(71.9)$ & 3.41 & $1.93-6.01$ & $<0.001$ & $317(90.1)$ & $272(76.0)$ & 2.51 & $1.54-4.07$ & $<0.001$ \\
\hline \multicolumn{11}{|l|}{ Concerns } \\
\hline Financial infusion & $268(82.5)$ & $247(74.6)$ & 0.98 & $0.60-1.60$ & 0.941 & $280(80.2)$ & $260(73.2)$ & 0.90 & $0.59-1.38$ & 0.629 \\
\hline Privacy concerns & $199(60.9)$ & $197(59.3)$ & 0.93 & $0.59-1.45$ & 0.739 & $200(56.7)$ & $190(52.9)$ & 0.94 & $0.63-1.40$ & 0.762 \\
\hline Discriminations & $139(42.0)$ & $147(44.3)$ & 0.83 & $0.53-1.28$ & 0.289 & $145(41.2)$ & $127(35.7)$ & 1.17 & $0.78-1.75$ & 0.459 \\
\hline Unexpected negative effects & $131(39.7)$ & $133(39.9)$ & 1.09 & $0.70-1.70$ & 0.696 & 117(33.1) & $112(31.1)$ & 0.97 & $0.63-1.49$ & 0.891 \\
\hline Cloned human beings & $114(34.5)$ & $122(36.9)$ & 0.85 & $0.54-1.34$ & 0.934 & $143(40.7)$ & $137(38.3)$ & 1.04 & $0.67-1.61$ & 0.872 \\
\hline \multicolumn{11}{|l|}{ Belief } \\
\hline Company or government & $161(49.4)$ & $137(41.4)$ & 1.32 & $0.89-1.94$ & 0.167 & $143(40.7)$ & 137 (38.3) & 0.89 & $0.61-1.29$ & 0.529 \\
\hline
\end{tabular}

${ }^{a}$ Adjusted according to age and formal education duration

experiences and familiarity with genetic testing are associated with positive attitudes toward it. In a nationwide study in Japan [17], those who had learned about genetics in school and had heard of the term "genetic testing" approved of the promotion of genomic studies. In Dutch studies [16, 23], the public attitude changed over time even though their experience with genetic testing had not increased. More people endorsed the ideas that "genetic knowledge helps people live longer" and "genetic study should be promoted" in 2010 than in 2002 . They suggested that the public do not perceive neonatal and prenatal screening tests as genetic tests. However, there is a chance that the public unconsciously glances over genetic issues in today's society. Condit [12] suggested that people accept a new technology as the natural order when it becomes familiar over time. Most citizens usually see genome studies as being outside of the natural order. The Nagahama study program was perceived as an extensive and free health check-up program that ultimately inspired 10,084 residents to become involved [14]. In this case, because of the number of participants, this method may be effective to familiarize the general public with genetic studies and its outcomes. Alhakami \& Slovic [29] suggested that people tended to judge the benefits as high when they felt the activity was favorable, which may apply in the case.
Lids et al. [30] clarified that research participants have a "personal" frame, while researchers have a "science" frame. Therapeutic misconception arises not from a lack of information but from a difference in cognitive frame. Therefore, they posit that scientific reframing of what is involved in a clinical trial is necessary. The Nagahama study has been promoted by the catchphrase "for your children and grandchildren" to avoid a "science" frame. One third of citizens live in their native community and one fourth of citizens live with their extended family consisting of more than three generations of family members [31]. Belief of the study's benefits for their children and grandchildren may attract them to participate and become aware of the benefits of the genome study.

Almost half of the respondents had a positive attitude toward donating their DNA for drug susceptibility genetic testing, while approximately $30 \%$ could not decide and roughly $20 \%$ had a negative attitude. A logistic regression analysis was conducted to explore the factors associated with willingness to participate in drug susceptibility genetic testing. According to the results, both males and females who had positive attitudes toward such testing had high levels of self-rated understanding of the terminology and a high degree of awareness of the benefits of genetic studies. 
Kobayashi and Satoh [32] used the Internet to explore Japanese attitudes toward pharmacogenomics research. Of their respondents, $45.3 \%$ had a positive attitude and $46.3 \%$ were neutral toward participating in pharmacogenomics research when taking medications. However, the willingness to participate increased to $61.7 \%$ positive and decreased to $30.6 \%$ neutral when experiencing severe adverse drug reactions. The proportion of respondents who refuse to participate was similar in both scenarios (8.3\% vs. $7.6 \%$, respectively) in their study. The reason for the disparity between Kobayashi's study and ours could be the use of the Internet and a correspondingly higher interest in scientific issues compared with those in the present study.

Haga et al. [33] investigated the American public's attitude toward pharmacogenomics research. Of their respondents, $92 \%$ had positive attitudes toward testing to assist with drug selection and $73 \%$ approved of testing to predict mild side effects. Respondents in their study were markedly more positive compared with respondents in our and Kobayashi's studies [32]. Ishiyama et al. [17] assume that Japanese tend to be prudent in decision-making. Our results support them.

In addition, $78 \%$ of respondents in the Haga et al. stated they were unwilling to undergo drug susceptibility genetic testing if their DNA or test results would be shared without their permission [33]. The authors suggest that the respondents might be unaware that federal law bans genetic discrimination by health insurers or employers, which may have effected their results. In the present study, the belief that companies or government bodies may use genetic information was not associated with willingness toward testing. Nagahama city government enacted an ordinance, the "Nagahama Rule," to manage the Nagahama study. The mission was to prioritize citizens' dignity and that might have encouraged citizens' trust in the study.

Awareness of the project contents was associated with the willingness to participate in drug susceptibility genetic testing in males but not in females. According to a review by the Office of Science and Technology and the Wellcome Trust [34], the supporters of science tend to be self-confident, and they generally have trust in the government and higher authorities. Recruitment for the Nagahama study was achieved through various public information channels as well as word-of-mouth communications. Thus, males who were inactive in their respective community associations were less aware of the Nagahama study, whereas females were more aware because volunteering was a routine community activity for them [14]. Conversely, males who were active in their community associations generally trusted regulatory systems. This might explain why the positive attitudes toward drug susceptibility genetic testing associated with the awareness of Nagahama study were only seen in males. For females, just being aware of communitybased genome studies did not change the willingness to participate in drug susceptibility genetic testing. Females may be able to bring themselves to donate DNA toward genetic testing if they feel familiar with the genetic terminology. Condit [12] suggests that people tend to perceive a certain category as the natural state of affairs when the given category is familiar to them. For example, people may agree to donate their DNA for drug susceptibility genetic testing without reluctance if their family members and if trusted confidants recommend such involvement. Moreover, as Lids et al. suggest, it is necessary to provide information appropriate to the public's cognitive frame of personal needs for drug susceptibility genetic testing. As genome cohort study is coherently the project to promote public health through the development of medicine within a "science frame," while "extensive and free health check-up," "study for your children and grandchildren," and "genetic testing for revealing of association between drug effectiveness or drug adverse reaction and genomic markers" are different things within a "personal frame." Timely and consecutive communication is required because the results are obtained a long time after participants provide consent for the study.

The present study has several limitations. First, participants were dichotomized into respondents who were aware of the project's contents and those who didn't know about the study at all; however, this approach may have introduced bias. In fact, those who were aware of the project contents were generally involved in community activities, were health conscious, and had trust in the government. This self-selecting bias may have altered the results.

Second, this study itself may become a public relation tool for the Nagahama study, and consequently, influence respondents' attitudes toward genetic research. However, we found that the attitude of subjects who were aware about the study contents before the study period was significantly different from that of subjects who did not know about the study content before the study period. This difference persisted even if subjects who were unaware of the contents gained knowledge during the study period.

Third, self-rated understanding of terminology may not indicate true comprehension. According to Ladwig et al. [24], perceived knowledge affects understanding in a different way than factual knowledge. Perceived knowledge could be influenced by specific heuristics, whereas factual knowledge could not. Hypothetically, perceived knowledge is more supportive of technology. Future studies should investigate the differences of influence between perceived and factual knowledge for public 
understanding of genome study. Finally, this study involved cooperation between the local government and a university, which is a rare scenario in Japan. Thus, the results of such collaboration may not apply to other communities.

It is necessary to conduct future research about the gap between the awareness of the benefits of genome study and the willingness to undergo drug susceptibility genetic testing. We hope to conduct a series of interviews to explore the reasons for negative attitudes toward drug susceptibility genetic testing, which might be a potential abhorrence, differences in context, the misconception as specific treatment for serious diseases but general diagnose, lack of information, or a matter of communication.

\section{Conclusions}

This study examined how a community-based genome cohort study affects the attitudes of the general public toward such projects. In this case, the Nagahama study was perceived by the residents as a reasonable health check-up program, which eventually helped familiarize them with genetic studies and earn their intuitive trust. However, even though similar projects can promote greater awareness of the benefits of genetic studies, awareness may not always lead to greater willingness to participate in genome studies and clinical applications. In particular, females did not display willingness to participate in related activities, such as drug susceptibility genetic testing. This indicates that some citizens feel genome studies are unfamiliar and risky. Luhmann [35] stated that "Trust is based on a circular relation between risk and action," and "Familiarity is an unavoidable fact of life; trust is a solution for specific problems of risk." Genome studies, in which a subject or their acquaintances participated along with the possibility that the studies could improve the health of children and grandchildren, engender a perception of less risk and greater familiarity. Certainly, the Nagahama study may be understood as a free and extensive health check-up program to some degree. However, it would be probably safe to assume that familiarity leads to understanding and future action because trust does not work in an unfamiliar world.

\section{Competing interests}

The authors declare that they have no competing interests.

\section{Authors' contributions}

MK performed the data analysis and wrote the manuscript, MK and IM interpreted the results, and MK and NT developed the study design and protocol. All authors read and approved the final manuscript.

\section{Acknowledgements}

We would like to thank the citizens of Nagahama and the Nagahama City Health Promotion section for their cooperation in this research. This project was supported in part by the "Nagahama Regional Open Genome Epidemiology Study" of RISTEX in the Japan Science and Technology Agency.

\section{Author details}

'Department of Medical Communication, Kyoto University School of Public Health, Yoshidakonoe-cho, Sakyo-ku, Kyoto \#6068501, Japan. ${ }^{2}$ Department of Health Infomatics, Kyoto University School of Public Health,

Yoshidakonoe-cho, Sakyo-ku, Kyoto \#6068501, Japan.

Received: 18 November 2014 Accepted: 7 March 2016

Published online: 15 March 2016

\section{References}

1. Feero WG, Guttmacher AE. Genomewide association studies and assessment of the risk of disease. N Engl J Med. 2009;363:166-76.

2. Masui T, Takada Y. Ethical, legal, and social issues of genome research-new phase of genome research desperately requires social understanding and safeguards on the use of medical records and other personal information. Yakugaku Zasshi. 2003;123:107-19.

3. Yonemoto S. Bioethical issues and bio-politics in the world and Japan. Rinshō ketsueki. 2007:48:1339-44.

4. Burke W, Laberge AM, Press N. Debating clinical utility. Public Health Genomics. 2010;13:215-23.

5. Evans JP, Meslin EM, Marteau TM, Caulfield T. Genomics. Deflating the genomic bubble. Science. 2011;331:861-2.

6. Khoury MJ. Dealing with the evidence dilemma in genomics and personalized medicine. Clin Pharmacol Ther. 2010;87:635-8.

7. Leighton JW, Valverde K, Bernhardt BA. The general public's understanding and perception of direct-to-consumer genetic test results. Public Health Genomics. 2012;15:11-21.

8. Pearson YE, Liu-Thompkins Y. Consuming direct-to-consumer genetic tests: the role of genetic literacy and knowledge calibration. J Public Policy Mark. 2012:31:42-57.

9. Crews KR, Hicks JK, Pui CH, Relling MV, Evans WE. Pharmacogenomics and individualized medicine: translating science into practice. Clin Pharmacol Ther. 2012;92:467-75.

10. Green ED, Guyer MS, Institute NHGR. Charting a course for genomic medicine from base pairs to bedside. Nature. 2011;470:204-13.

11. Tremblay J, Hamet P. Role of genomics on the path to personalized medicine. Metabolism. 2013:62:52-5.

12. Condit CM. Public attitudes and beliefs about genetics. Annu Rev Genomics Hum Genet. 2010:11:339-59.

13. Khoury MJ, Jones K, Grosse SD. Quantifying the health benefits of genetic tests: the importance of a population perspective. Genet Med. 2006;8:191-5.

14. Miyamoto $K$, Iwakuma $M$, Nakayama T. Residents' awareness and attitudes about an ongoing community-based genome cohort study in Nagahama, Japan. Public Underst Sci. 2015;24:957-69.

15. Etchegary H, Cappelli M, Potter B, Vloet M, Graham I, Walker M, Wilson B. Attitude and knowledge about genetics and genetic testing. Public Health Genomics. 2010;13:80-8.

16. Henneman L, Timmermans DR, Van der Wal G. Public experiences, knowledge and expectations about medical genetics and the use of genetic information. Community Genet. 2004;7(1):33-43.

17. Ishiyama I, Nagai A, Muto K, Tamakoshi A, Kokado M, Mimura K, Yamagata Z. Relationship between public attitudes toward genomic studies related to medicine and their level of genomic literacy in Japan. Am J Med Genet A. 2008;146:1696-706.

18. Kerath SM, Klein G, Kern M, Shapira I, Witthuhn J, Norohna N, et al. Beliefs and attitudes towards participating in genetic research-a population based cross-sectional study. BMC Public Health. 2013;13:114.

19. Kettis-Lindblad $\AA$, Ring L, Viberth E, Hansson MG. Genetic research and donation of tissue samples to biobanks. What do potential sample donors in the Swedish general public think? Eur J Public Health. 2006;16:433-40.

20. Haga SB, Barry WT, Mills R, Ginsburg GS, Svetkey L, Sullivan J, et al. Public knowledge of and attitudes toward genetics and genetic testing. Genet Test Mol Biomarkers. 2013;17:327-35.

21. Jallinoja P, Aro AR. Does knowledge make a difference? The association between knowledge about genes and attitudes toward gene tests. J Health Commun. 2000;5:29-39.

22. Sturgis $P$, Allum N. Science in society: re-evaluating the deficit model of public attitudes. Public Underst Sci. 2004;13:55-74. 
23. Capon A, Gillespie J, Rolf M, Smith W. Perceptions of risk from nanotechnologies and trust in stakeholders: a cross sectional study of public, academic, government and business attitudes. BMC Public Health. 2015;15:424

24. Ladwig P, Dalrymple KE, Dominique B, Scheufele DA, Corley EA. Perceived familiarity or factual knowledge? Comparing operationalizations of scientific understanding. Sci Public Policy. 2012;1-14.

25. Liang X, Ho SS, Brossard D, Xenos MA, Scheufele DA, Anderson AA, Hao X, He X. Value predispositions as perceptual filters; comparing of public attitudes toward nanotechnology in the United States and Singapore. Public Underst Sci. 2015;24:582-600.

26. Henneman L, Vermeulen E, van El CG, Claassen L, Timmermans DR, Cornel MC. Public attitudes towards genetic testing revisited: comparing opinions between 2002 and 2010. Eur J Human Genet. 2012;21:793-9.

27. Tomoda M. Evaluating the current attitude toward practice and research on human genetics in Japan. Kyoto University School of Public Health Master Thesis. 2007;7:173-80 (in Japanese).

28. Gottweis H. Gene therapy and the public: a matter of trust. Gene Ther 2002;9:667-9.

29. Alhakami AS, Slovic P. A psychological study of the inverse relationship between perceived risk and perceived benefit. Risk Anal. 1994;14:1085-96.

30. Lids CW, Albert K, Appelbaum P, Dunn LB, Overton E, Pivovarava E. Why is therapeutic misconception so prevalent? Camb Q Healthc Ethics. 2015;24:231-41.

31. Miyamoto K, Iwakuma M, Nakayama T. Social capital and health: implication for health promotion by lay citizens in Japan. Glob Health Promot. 2014 (Epub ahead of print).

32. Kobayashi $E$, Satoh N. Public involvement in pharmacogenomics research: a national survey on public attitudes towards pharmacogenomics research and the willingness to donate DNA samples to a DNA bank in Japan. Cell Tissue Bank. 2009;10:281-91.

33. Haga SB, O'daniel JM, Tindall GM, Lipkus IR, Agans R. Survey of U.S. public attitudes towards pharmacogenetics testing. Pharmacogenomics J. 2012;12:197-204.

34. Office of Science and Technology and the Wellcome Trust. Science and the public: a review of science communication and public attitudes toward science in Britain. Public Underst Sci. 2001;10:315-30.

35. Luhmann N. Familiarity, confidence, trust: problems and alternatives. Trust: Making and breaking cooperative relations. 2000;6:94-107.

\section{Submit your next manuscript to BioMed Central and we will help you at every step:}

- We accept pre-submission inquiries

- Our selector tool helps you to find the most relevant journal

- We provide round the clock customer support

- Convenient online submission

- Thorough peer review

- Inclusion in PubMed and all major indexing services

- Maximum visibility for your research

Submit your manuscript at www.biomedcentral.com/submit 